\title{
Karyotype studies among children with severe visual handicap
}

\author{
G. R. FRASER, ${ }^{*}$ A. I. FRIEDMANN,1 J. D. A. DELhANTY, ${ }^{2}$ \\ J. H. EDWARDS, 3 A. M. GLEN-BOTT, 4 J. INSLEY,3 \\ K. P. LELE, $2 * *$ U. MITTWOGH, ${ }^{2}$ and D. MUTTON $5 * * *$
}

From the Godfrey Robinson Unit (Royal National Institute for the Blind), ${ }_{1}$ Debartment of Research in Ophthalmology, Royal College of Surgeons, London; the Galton Laboratory, ${ }^{2}$ University College, London; the Institute of Child Health, ${ }^{3}$ Children's Hospital, Birmingham; the Department of Anatomy, ${ }^{4}$ St. Thomas' Hospital Medical School; and the Paediatric Research Unit, ${ }^{\mathbf{5}}$ Guy's Hospital Medical School, London

During $1963-65$, a survey was made of the causes of severe visual handicap, in many cases amounting to complete blindness, among 776 children in special schools in England and Wales (Fraser and Friedmann, 1967). In twelve of these children (Cases 1, 4, 5, 6, $7,8,14,18,19,20,21,22 \dagger)$, it was possible to perform karyotype studies during the survey, and in one (Case $2 \dagger$ ) the chromosomes of a member of the family were examined. In nine further instances (Cases 9, 10, I I, 12, I 3, I 5, 16, I 7, 23 $\dagger$ ), karyotype analyses had been performed elsewhere, and the results were available; in Case $3 \dagger$ results were available concerning two similarly affected cousins.

In all, therefore, karyotyping was performed, either of the children themselves or (in Cases 2 and 3) of members of their families, in 23 of the 776 subjects of the survey. These children were selected mainly because of unusual constellations of abnormalities; such examinations, however, were also made because of unusual patterns of inheritance of the visual defect.

\section{Case reports}

In all these cases, normal karyotypes were found. Basic additional data about the 23 cases investigated are presented in the Table and Pedigrees A to G (overleaf). Screening of the urine was performed in all cases for reducing substances, phenylketones and albumin; in addition, the amino acid excretion patterns were examined chromatographically. No abnormal results were obtained.

Case I (Pedigree A, IV, 2)

This girl is probably a heterozygote for sex-linked choroideremia. Such heterozygotes normally show minor changes in their fundi, usually without symptoms. Case 1 , however, is involved as severely as any affected male, and a discussion of the possible reasons for this unusual occurrence has been published (Fraser and Friedmann, 1968).

Received for publication August 6, r969

Address for reprints: Dr. G. R. Fraser, Division of Medical Genetics (as below)

Present Addresses

* Division of Medical Genetics, Department of Medicine, University of Washington, Seattle, Washington 98 ro5, U.S.A.

** Department of Pharmacology, New York University Medical Center, 550 First Avenue, New York, New York roor6, U.S.A.

*** Royal Marsden Hospital, Surrey Branch, Downs Road, Sutton, Surrey. 
Table Basic data about children studied

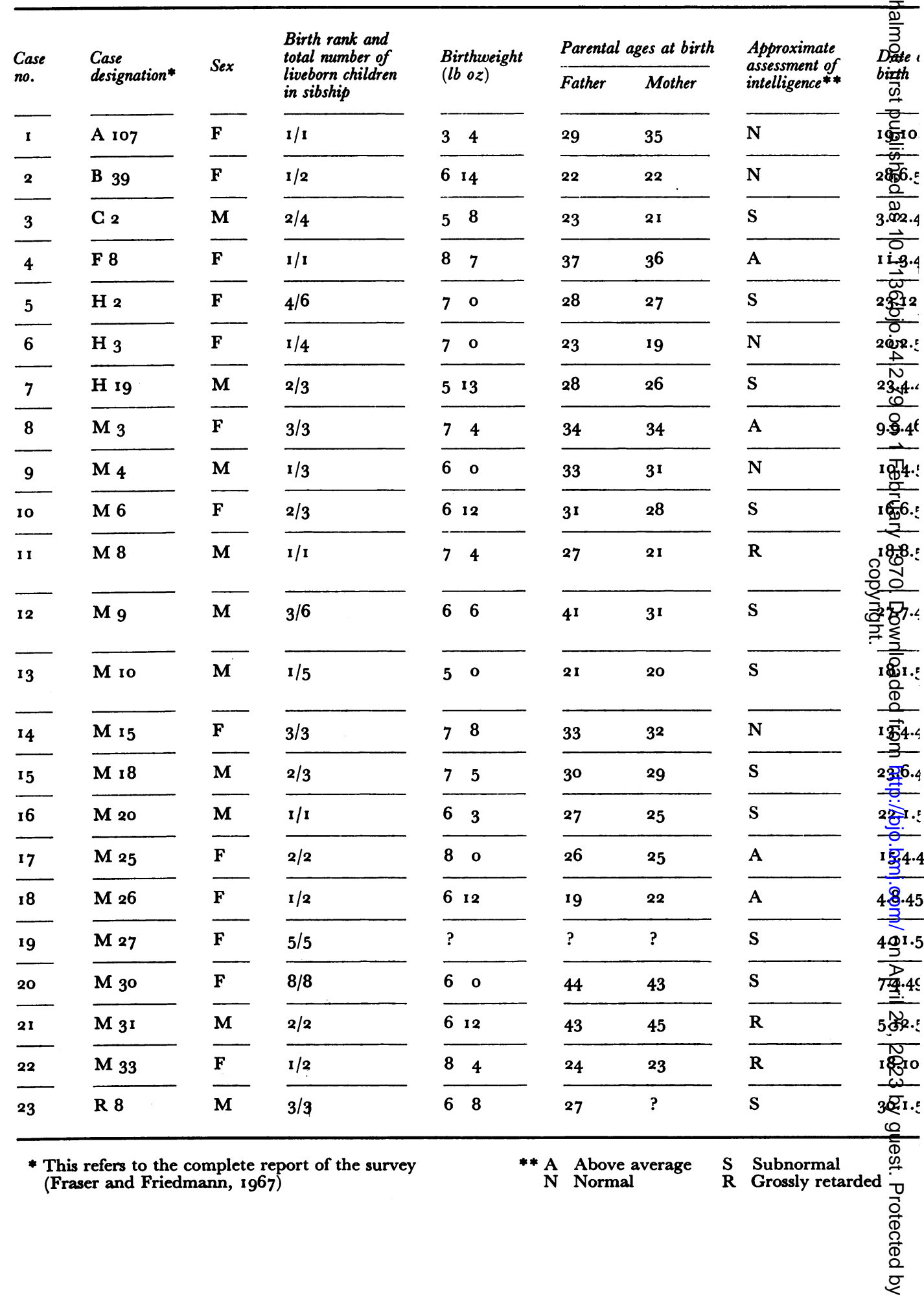


zgnosis

เoroideremia

tinoblastoma

sudoglioma

fantile retinal detachment

icrophthalmos

icrophthalmos

Iophthalmos; camptodactyly

ndrome of Hallermann-Streiff-François

eger's mesodermal dysgenesis of anterior segment

yptophthalmos; complex malformation

rsplasia spondyloepiphysaria congenita; deafness; myopia; retinal detachments; secondary tis and cataracts

ssibly dysplasia spondyloepiphysaria congenita; deafness; myopia; retinal detachments; zondary iritis and cataracts

sssibly dysplasia spondyloepiphysaria congenita; deafness; retinal detachments; secondary tis and cataracts

iphthalmos; megalocornea; hirsutism; skeletal dystrophy

igh myopia; cataracts; deafness; skeletal dystrophy

ptic atrophy; megalocornea; complex malformation

ataracts; dental deformities; webbed toes; amenorrhoea

Microphthalmos; cataracts; dental deformities; webbed toes

ficrophthalmos; lens and corneal opacities; dwarfism; cleft palate; micrognathia

igh myopia; optic atrophy; polydactyly of hands and feet

ctreme microphthalmos; complex malformation

ultiple dermoid tumours of eyes and orbits

ptic atrophy caused by subdural haematoma; abnormal facics
Inheritance

Sex-linked recessive (pedigree $\mathrm{A}$ )

Dominant (pedigree B)

Sex-linked recessive (pedigree $\mathbf{C}$ )

?Dominant ?Sex-linked

?Dominant

?Dominant

?

?Dominant

Dominant

Recessive

Dominant

\section{?Dominant}

?Dominant

?Recessive

Recessive

?

?Dominant

?Dominant

?

?

?

?

? 

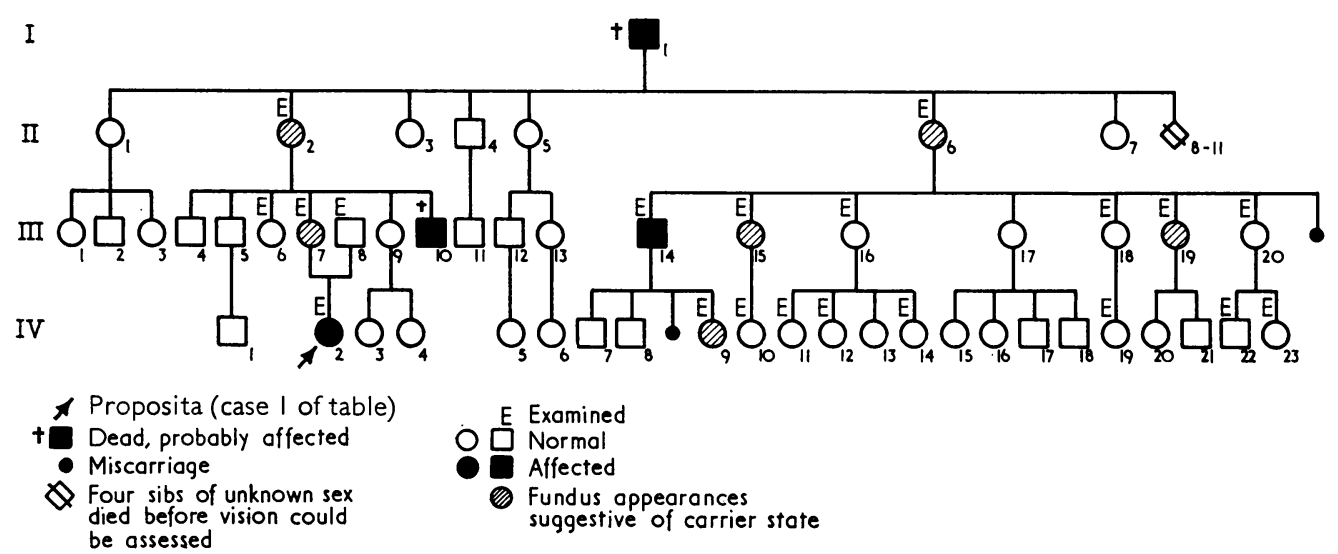

Q Four sibs of unknown sex died before vision could be assessed

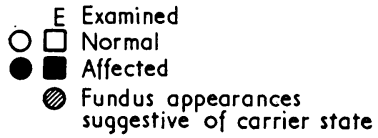

PEDIGREE A The proposita (IV 2) is Case I in the Table, a manifesting heterozygote for a sex-linked choroideremia

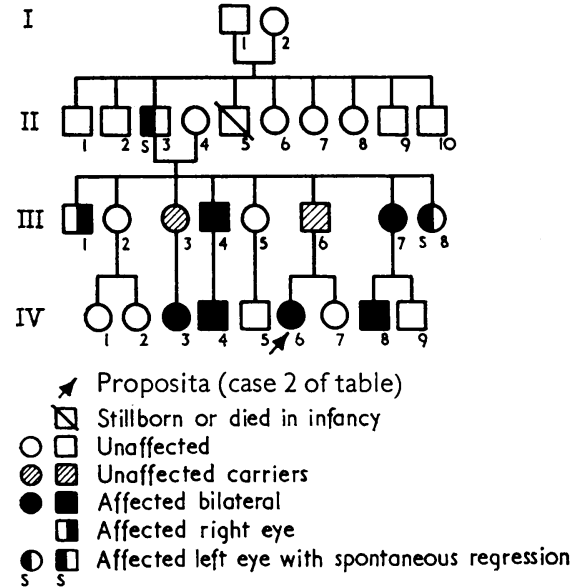

PEDIGREE B The proposita $(I V 6)$ is Case 2 in the Table and has bilateral retinoblastoma. The chromosomes of her father (III 6), who although normal is clearly carrying the gene responsible for retinoblastoma in this family, were studied

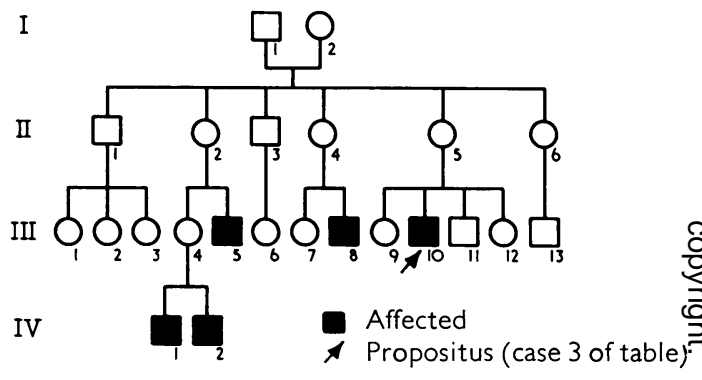

PEDIGREE C The propositus (III IO) is Case 3 in the Table and has sex-linked pseudoglioma. The chromosomes of his first cousins once removed, IV I and IV 2, were studied

Case 2 (Pedigree B, IV, 6)

Retinoblastoma is often inherited in a dominant manner, especially the bilateral variety. This family (Pedigree B) shows unusual features, in that both unilateral and bilateral forms occur and spontaneous regression appears to be relatively frequent. Also, at least two persons (III, 2 and 6) who are carrying the responsible gene have no tumour at all. The karyotype of one of these (III, 6-the father of Case 2) was examined and found to be normal; the specimen of skin taken from Case 2, unfortunately, failed to grow.

Case 3 (Pedigree C, III, Io)

This boy is a typical example of sex-linked pseudoglioma. This condition is often associated, as in this family, with mental retardation (Warburg, 1966). Karyotype analysis had been per- 
formed on two maternal first cousins once removed of the propositus (C, IV, I and 2) and the results were reported as normal by Forrester ( 1963 ). One eye of the propositus has been enucleated and histological section showed rosettes, similar to those described in "retinal dysplasia" by Reese and Straatsma (1958), which gave rise to a diagnosis, in all probability erroneous, of retinoblastoma.

\section{Case 4}

This girl had congenital retinal folds resulting in total retinal detachments and secondary cataracts at the age of 5 years; the history of her father was similar.

\section{Case 5}

This girl had bilateral microphthalmos and has two brothers with bilateral colobomata of the iris, choroid, and retina, as well as a normal brother and two normal sisters. The mother has poor vision, the cause of which is unknown.

\section{Case 6}

This girl has bilateral and her sister unilateral microphthalmos with persistent pupillary membrane. Her father has moderate microphthalmos, nystagmus, and poor vision.

\section{Case 7}

This boy has bilateral anophthalmos and camptodactyly of both fifth fingers. His mother was treated with thiouracil throughout pregnancy for thyrotoxicosis. There is no family history of visual defects.

\section{Case 8}

This girl has the complete syndrome of Hallermann-Streiff as described by François (1958). Her defects include congenital cataracts, microphthalmos, choroido-retinal lesions affecting primarily the macula, hypotrichosis, dwarfism, dental malformations, and a characteristic widespread deformity of the skull with hypoplasia of the facial bones (especially the mandible) and with wide separation of the lambdoid and sagittal sutures. In addition, there was hypertrophy of the occipital condyles and the lateral parts of the atlas. There is no family history of visual defects or of these associated anomalies.

This girl was reported by Gregory (1955), and her photographs, taken from that report, are reproduced by François (1958).

\section{Case 9}

This boy has glaucoma associated with partial aniridia in the right eye and complete aniridia in the left. In addition, he has considerable hypoplasia of the maxilla, low-set bat-ears, umbilical hernia, and anal stenosis. His brother is similarly affected except that malformed irides are present in both eyes giving rise to slit pupils. The mother of these two boys also had slit pupils and malformed irides, and the maternal grandmother has suffered from glaucoma for many years, though it is not known whether this has been associated with malformation of the iris.

This family was described by Crawford (1967) as a probable variant of Rieger's mesodermal dysgenesis of the anterior segment (Rieger, 1935). The karyotypes of the mother and both affected boys were normal.

\section{Case ro}

This girl suffers from the autosomal recessive syndrome of cryptophthalmos. In her case, this complex and variable syndrome comprises deafness due to middle and outer ear malformations, high palate, webbing of fingers and toes, atresia of the larynx, wide separation of the symphysis pubis, anal stenosis, and masculinization of the external genitalia. A similarly affected sister died a few hours after birth because of renal aplasia which is frequently present in this condition. The parents are normal except that the father has slight microphthalmos, and the mother has a degree of blepharochalasis; these findings may represent mild heterozygote manifestations. This case has been described by Fraser (1962, 1964, 1966). 


\section{Case I I}

This boy is dwarfed because of widespread skeletal dystrophy. He has congenital cystic detachments of the retina, associated with myopia and resulting in secondary iritis, glaucoma, and cataracts. $\mathrm{He}$ (as well as Cases 12 and I3) has been studied independently by Roaf, Longmore, and Forrester (1967), and the $x$ rays reproduced in that report leave no doubt that this skeletal dystrophy is of the type of dysplasia spondyloepiphysaria congenita (Spranger and Wiedemann, 1966a, 1966b; Bach, Maroteaux, Schaeffer, Bitan, and Crumière, 1967). This entity is discussed further below. Cleft palate has been reported in cases of this condition; it was present at birth in Case I I and was subsequently repaired. There is some evidence of moderately severe hearing impairment affecting primarily tones of high frequency. There is no family history of visual defect or of these associated anomalies.

\section{Case 12}

This boy is dwarfed because of widespread skeletal dystrophy. Unfortunately, no $x$ rays were available for examination, but the clinical history and a single $x$ ray of the knee reproduced by Roaf and others (1967) suggest that the condition may be dysplasia spondyloepiphysaria congenita. The patient is blind because of high myopia, leading to retinal detachments, secondary iritis, and cataracts. He has moderately severe deafness of a mixed conductive and perceptive type noted since the age of 7 years. There is no family history of visual defect or of these associated anomalies.

\section{Case 13}

This boy has a widespread skeletal dystrophy but is not notably dwarfed, being $5^{\mathrm{I}}$ inches tall at the age of $\mathrm{I} 2$ years. He differs in other respects from Case $I I$ in that he does not have the round face with flattened nasal bridge and slightly protruding eyes which characterizes cases of dysplasia spondyloepiphysaria congenita. Moreover, several series of skeletal $x$ rays taken in infancy and early childhood were available for examination and showed a much less significant involvement of the hips and pelvis than is usually seen in dysplasia spondyloepiphysaria congenita. Nevertheless, the visual lesion is strikingly similar to those of Cases $\mathrm{I}$ I and $\mathrm{I} 2$ in that the patient was known to have? had poor eyesight since infancy and, by the age of 6 years, he already had bilateral long-standing secondary iritis with complicated cataract in the right eye and widespread retinal detachment in the left. At the time of the survey when he was aged 12 years, he had iritis with calcified lenses and superficial peripheral corneal opacities. Moreover, he had mild perceptive hearing loss affecting predominantly tones of high frequency. There is no family history of visual defect or of these related anomalies.

\section{Case 14}

This girl has megalocornea and buphthalmos. Operations for the buphthalmos were followed by retinal detachments and secondary cataracts. In addition, she has marked hirsutism with no detectable endocrine basis and an abnormal facies with a flattened nasal bridge. Her fontanelles closed only at 3 years of age; an air encephalogram showed slight to moderate ventricular enlargement. The brow ridges are prominent, and she has a midline ridge on the occipital bone. The upper second molar teeth have five cusps bilaterally. She has spatulate hands. Qualitative screening of the urine for excess of acid mucopolysaccharides was negative. There is no family history of visual defect or of these associated anomalies.

\section{Case 15}

This boy has congenital high myopia in both eyes. An operation for cataract in the left eye was performed at 16 months of age. Vitreous haemorrhages and retinal detachments subsequently occurred in both eyes leading to blindness. He has severe perceptive deafness first detected in infancy. A cleft palate was noted at birth as well as profound deformity of skull structure with wide open fontanelles; the parietal and frontal bone formation was so defective when he was born that he was mistakenly diagnosed as an anencephalic. He had club hands and club feet at birth 
which have improved with orthopaedic treatment. The parents are first cousins. There is no family history of visual defect or of these associated anomalies; a paternal first cousin is said to be suffering from Down's syndrome (mongolism).

\section{Case 16}

This boy has infantile optic atrophy and megalocornea. He shows microcephaly and hypertelorism. $\mathrm{He}$ is an epileptic and has cerebral palsy of athetoid type. Rectal biopsy showed extensive sudanophilic demyelination of myelin sheaths and marked neuronal satellitosis. There is no family history of visual defect or of these associated anomalies.

\section{Case 17}

This girl has congenital cataracts associated with webbed toes and dental deformities. There is no family history of visual defect, but both she and her sister, aged at the time of the survey 24 and 20 years respectively, have primary amenorrhoea.

\section{Case 18}

This girl has congenital cataracts with microphthalmos associated with dental deformities and webbed toes. Her mother has been blind in one eye from birth, but the cause of this defect is not known.

\section{Case 19}

This girl has microphthalmos, with eccentric pupils, and lenticular and corneal opacities. She is dwarfed ( $3 \mathrm{ft}$ at 6 years) and has cleft palate and micrognathia. There is no family history of visual defect or of these associated anomalies.

\section{Case 20}

This girl has high myopia and optic atrophy associated with polydactyly of hands and feet and obesity. There is no family history of visual defect or of these associated anomalies.

\section{Case 21}

This boy has extreme bilateral microphthalmos and an angioma of the lower lid. In addition, he shows lumbar spina bifida occulta, hiatus hernia, hypospadias, deformed auricles, and undescended testicles. The mother had a diagnostic $x$ ray examination when she was 7 weeks pregnant. There is no family history of visual defect; a previously stillborn sister was anencephalic.

\section{Case 22}

This girl has a dermolipoma of the left orbit, leading to proptosis of the eye and ulceration of the cornea, and also dermoid tumours of the right conjunctiva and optic nerve sheath. She is deaf and epileptic and has an abnormal electroencephalogram. Her mother was a radiographer and was exposed to $x$ rays throughout her pregnancy; in addition, she had influenza when 2 months pregnant. There is no family history of visual defects or of related conditions.

\section{Case 23}

This boy has optic atrophy and deafness, caused by a subdural haematoma after an accident at the age of 2 years. He has an abnormal face and short limbs. He suffers from gangrene of the tip of the nose, fingers, and toes. There is no family history of visual defect or of these associated anomalies.

\section{Discussion and conclusions}

In all 23 families investigated, only normal karyotypes were found on examination of skin and/or blood cells. While serious ocular involvement is extremely common in known syndromes due to chromosomal aberrations (for a comprehensive review, see François, 
1967), most of such children are mentally retarded and those showing many of these syndromes, especially those due to $\mathrm{D}$ and $\mathrm{E}$ trisomy, do not survive infancy. Since the children surveyed here constituted essentially an educable group, it is clear that the mentally retarded blind are grossly under-represented. Nevertheless, some of these children were considered to be only trainable rather than educable and, according to the rough assessment of intelligence (Table), three of the 23 studied were grossly mentally retarded. In addition, no less than nine were educationally subnormal, the remainder being of normal or superior intelligence. As far as possible, these assessments were made independently of the educational handicap associated with the visual defects of the children concerned.

In Case I, chromosomal examination was undertaken to investigate an apparent anomaly in the pattern of sex-linked recessive or intermediate inheritance normally associated with choroideremia. This girl is exceptional in that only one other apparent heterozygote for sex-linked choroideremia showing severe and early involvement has been described (Harris and Miller, I968). In view of this, very careful investigations were made of her karyotype from repeated skin biopsies and blood specimens. All these examinations and additional studies of the sex chromatin in buccal smears and skin fibroblast cultures gave no indication of any deviation from a normal female karyotype.

Chromosomal abnormalities have been reported several times in cases of retinoblastoma (Day, Wright, Koons, and Quigley, I963; Lele, Penrose, and Stallard, I963; Thompson and Lyons, 1965; van Kempen, I966; Wilson, Melnyk, and Towner, I969), and the unusual pattern of inheritance in the family of Case 2 (Pedigree B) was considered to be a sufficient indication for chromosomal study. Similar pedigrees have been reported by Steward, Smith, and Arnold (1956) and by Watillon, Weeks, Mairiaux, and Joaching ( 1964$)$.

The normal chromosomal findings in Case 3 (Pedigree C) confirm other results in cases of sex-linked pseudoglioma (Warburg, 1966).

Certain features of the retinal detachments in Case 4 and her father were not typical of the usual autosomal dominant variety. Thus, congenital retinal folds were noted in this girl, and, both in her case and that of her father, retinal detachments had occurred by the age of 5 years. Furthermore, myopia was never a feature of her condition nor of that of her father. It was thought possible, therefore, that a sex-linked type of retinal detachment was involved, but this would involve full expression of the condition in a heterozygous female (as in the choroideremia of Case I), and the normal karyotype renders this explanation unlikely. It seems more probable that this family represents an atypical form of autosomal dominant retinal detachment.

Lele, Dent, and Delhanty (1965) have described colobomatous lesions of the iris associated with a chromosomal abnormality although they concluded that, in their patient, it was doubtful whether the relationship of the two was a causal one. Allderdice, Davis, Miller, Klinger, Warburton, Miller, Allen, Abrams, and McGilvray (i 969), however, came to the conclusion that both microphthalmos and colobomatous defects of the iris and retina were fairly frequent components of a syndrome which they defined as being due to a deletion affecting chromosome 13 in the $\mathrm{D}$ group. Irregular dominant inheritance is characteristic of the microphthalmos-with-coloboma group of lesions and the chromosomes of two children from this series with this type of lesion and this pattern of inheritance (Cases 5 and 6) were studied. In both cases, normal karyotypes were found.

The syndrome of Hallermann-Streiff-François is probably inherited in a dominant manner (Guyard, Perdriel, and Ceruti, I962), and Case 8 may represent a freshly arisen 
mutation. Rieger's (1935) mesodermal dysgenesis of the anterior segment, present in Case 9 and several affected relatives, is certainly inherited in an autosomal dominant manner. Apart from other features often associated with this condition, this boy and his affected brother have anal stenosis; this association with defects of the iris was previously reported by Brailey ( 1890$)$. While karyotype studies in Case 9 and his affected relatives afforded normal results, it is of considerable interest to note that Schachenmann, Schmid, Fraccaro, Mannini, Tiepolo, Perona, and Sartori (1965) described a somewhat analogous constellation of abnormalities (coloboma of the iris, anal stenosis, and renal malformation) inherited in a dominant manner and associated with a specific chromosomal aberration. It would seem, therefore, that anal stenosis and abnormalities of the iris are associated in two distinct syndromes, one of which may be the result of a detectable chromosomal rearrangement. Dominant abnormalities of this type, in which multiple malformations are associated, may well often reflect a chromosomal rearrangement rather than a point mutation, but this would have to be quite large to be detected microscopically and, in general, there must be a great number of such small aberrations which cannot be observed by present-day methods.

The entity of cryptophthalmos (Case 10) may represent the expression in homozygous form of a gene which causes mild ocular anomalies in heterozygous form (the blepharochalasis of the mother and the microphthalmos of minor degree of the father). This wide-spread malformation syndrome is often lethal since it may include gross renal hypoplasia, and survivors such as Case ro may be regarded as "Durchbrenner" or "escapers" in the sense of Hadorn (1955), meaning persons who have crossed a threshold of expression of a gene below which non-viability results. Masculinization of the external genitalia is common in females with this condition (Fraser, 1966) and may give rise to ambiguity of sex. In fact, Case Io was originally thought to be a boy before sex chromatin studies indicated that she had an XX sex-chromosome complement. This was subsequently confirmed by chromosome studies.

Cases I I to 13 form part of a larger series of children uncovered during this survey (Fraser, Friedmann, Maroteaux, Glen-Bott, and Mittwoch, I969) who manifest a generalized skeletal dystrophy, in some instances (including Case I I) corresponding exactly to the dysplasia spondyloepiphysaria congenita of Spranger and Wiedemann (r966a, r966b) and Bach and others ( 1967 ), together with high myopia causing blindness due to retinal detachment and secondary cataract, and moderately severe perceptive deafness. Clinical similarities within the entire group, especially regarding the nature of the visual lesion and the hearing loss, suggest that all these cases may represent phenotypic variation within the same basic genetically-determined disease. Such an identity cannot be proved, however, and the possibility cannot be excluded that two or more distinct conditions are represented within this group. Dysplasia spondyloepiphysaria congenita is probably inherited in a dominant manner (Spranger and Wiedemann, i966a, I966b) and isolated examples such as Cases I I, I 2, and I 3 presumably represent freshly arisen mutations.

Cases 14 and 15 represent ill-defined associations of skeletal dysplasias with blindness. The pattern of inheritance is probably autosomal recessive in Case 14, since a girl seen in this survey with a similar condition has a brother who is also affected. The condition of Case 15 is apparently unique and in his case autosomal recessive inheritance is suggested by the consanguinity of his parents.

Cases 17 and 18 are two of a group of three girls among the children surveyed who have congenital or infantile cataracts, associated with dental deformities and other minor malformations. The third of these girls (whose karyotype was not studied) has an ab- 
normality of the carrying angle of the elbows, and, especially in view of the primary amenorrhoea of Case I7, these constellations of abnormalities raised suspicions of the possibility of a chromosomal anomaly affecting the X-chromosomes. In the light of the normal karyotypes of Cases 17 and 18 , however, the exact nosological classification of this syndrome must remain in doubt.

In the remaining Cases ( $7,16,19$ to 23 ) unusual combinations of abnormalities occurred in a sporadic manner and the role of genetical factors in their causation is obscure.

While the possibility that the visual handicap of some of the 776 children surveyed is caused by a major structural chromosomal aberration has of course not been excluded, such associations are probably rare. The 23 families selected for study represent a large proportion of the children of the entire survey with unusual patterns of inheritance of visual defect or with bizarre constellations of congenital malformations. No example of any known syndrome connected with chromosomal aberrations was identified in the whole series and, as has been mentioned above, this is not unexpected, since only those children are represented who have survived infancy and are, in the main, educable. A boy with typical Down's syndrome, confirmed by karyotype study as being due to G-autosomal trisomy, was in fact seen at one of these special schools subsequent to the survey. He had been admitted for a trial period at the end of which it was decided that he was not educable. His severe visual defect was due to cataracts, which are often found in association with Down's syndrome.

These negative findings correspond to those of Leydhecker (1964) who studied seven persons with unusual eye malformations selected among the patients of a large ophthalmological clinic. It would seem advisable to repeat surveys of this type to search for relationships between detectable chromosomal abnormalities and eye defects among non educable mentally retarded persons selected through visual handicap.

Mention must be made, however, of the findings of Chrz, Neuwirth, Karel, and Klouček (1966). In a study which corresponded closely in its methods to the present one, these authors selected ten out of 284 children at schools for the visually handicapped in Prague for karyotype analysis. Of these ten children, two were thought to show an $\mathrm{X}$ isochromosome, two to have $\mathrm{E}$ trisomy, and two to have $\mathrm{G}$ trisomy. These results are all the more remarkable in that the phenotypes of these six children did not correspond to the syndromes normally associated with their karyotypic abnormalities. In the absence of further clarification of these anomalous results, the significance of these findings is difficult to assess.

\section{Summary}

Karyotype studies were made in 23 children (or members of their families) with visual handicap sufficiently severe to necessitate special education. They were selected from among the total of 776 studied either because of the presence of complex constellations of malformations in addition to the visual defect or because of unusual patterns of inheritance of the ocular lesion. No abnormal karyotypes were found, despite the high incidence of serious involvement of the eye in defined syndromes due to chromosomal aberrations.

We should like to thank the Principals and other staff of the schools which the subjects of this study attended for facilitating our visits and placing their time freely at our disposal. We are greatly indebted to the Royal National Institute for the Blind for their financial support of this survey of children with severe visual handicaps. We are grateful to Prof. P. E. Polani for his careful review of the manuscript and his many helpful suggestions. Lastly, we would like to thank the children themselves and their families for their unfailing courtesy and patience. 


\section{References}

Allderdice, P. W., DAVis, J. G., Miller, O. J., Klinger, H. P., WARburton, D., Miller, I). A., Allen,

F. H., JR., Abrams, C. A. L., and mcgilvray, e. (I969) Amer. J. hum. Genet., 21, 499

Bach, C., maroteauX, P., schaeffer, P., Bitan, A., and Grumière, c. (1967) Arch. franç. Pédiat., 24, 23

BRAILEY, W. A. (1890) Trans. ophthal. Soc. U.K., 10, I 39

GHRZ, R., NeuWirti, J., KARel, I., and klouček, A. F. (I966) Acta Fac. Med. Univ. Brun., 25, Ig I

CRAWFORD, R. A. D. (I967) Brit. 7. Ophthal., 51, 438

DAY, R. W., WRIGHT, s. W., KOONS, A., and QUIGLEY, M. (I963) Lancet, 2, I 54

FORRESTER, R. M. (1963) Proc. roy. Soc. Med., 56, 994

FrançoIs, J. (1958) A.M.A. Arch. Ophthal., 60, 842

- (1967) J. neurol. Sci., 40 5 I I

FRASER, G. R. (1962) Ann. hum. Genet., 25, 387

- (1964) J. med. Genet., I, 118

- (1966) Lancet, I, 1427

and Friedmann, A. I. (1967) "The Causes of Blindness in Childhood. A Study of 776

Children with Severe Visual Handicaps". Johns Hopkins Press, Baltimore

- (1968) Brit. med. J., 2, 732

- — MARoteaux, P., Glen-botr, A. м., and mittwoch, u. (1969) Arch. Dis. Childh.,

44, 490

GREGORY, I. D. R. (1955) Brit. J. Ophthal., 39, 44

GUYARD, PERdriel, G., and Ceruti, F. (1962) Bull. Soc. Ophtal. Fr., p. 443

IIADORN, E. (I955) "Letalfaktoren in ihrer Bedeutung für Erbpathologie und Genphysiologie der

Entwicklung". Thieme, Stuttgart

HARRIS, G. s., and Miller, J. R. (I968) Arch. Ophthal. (Chicago), 80, 423

KEMPEN, C. VAN (I966) Maandschr. Kindergeneesk., 34, 92

LELE, K. P., DENT, T., and DelhaNTY, J. D. A. (1965) Lancet, r, 576

- Penrose, L. S., and STAllard, H. B. (1963) Ann. hum. Genet., 27, I 7 I

Leydhecker, N. (1964) Klin. Mbl. Augenheilk., r44, $75^{\circ}$

ReESe, A. B., and STRAATSMA, B. R. (1958) Amer. J. Ophthal., 45, no. 4, pt 2, p. I99

RIEGER, H. (1935) v. Graefes Arch. Ophthal., r33, 602

ROAF, R., LONGMORE, J. B., and Forrester, R. m. (1967) Develop. Med. Child Neurol., 9, 464

SChachenmanN, G., SChmid, W., Fraccaro, M., MANNini, A., Tiepolo, L., Perona, G. P., and SARTORi,

E. (1965) Lancet, 2, 290

SPRANGER, J., and WIEDEMANN, H.-R. (1966a). Ibid., 2, 642

$-(1966 \mathrm{~b})$ Helv. paediat. Acta, 21, 598

STEWARD, J. K., SMITH, J. L. s., and ARNOLD, E. L. (1956) Brit. J. Ophthal., 40, 449

THOMPSON, H., and Lyons, R. B. (1965) Human Chromosome Newsletter, no. 15, p. 2 I

WARBURG, M. (I966) “Norrie's Disease", Acta ophthal. (Kbh.), Suppl. 89

Watillon, M., Weekers, R., mairiaux, e., and Joachim, м. (ig64) Arch. Ophtal. (Paris), 24, 279

Wilson, M. G., MELNYK, J., and TOWNER, J. W. (ig69) J. med. Genet., 6, 322 